\title{
Study of Urban Settlements Environment from a Health Perspective
}

\author{
Yu Qin ${ }^{1 *}$

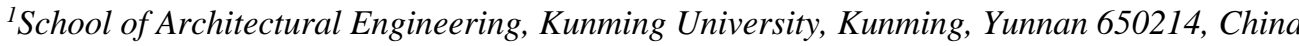 \\ *Corresponding author. Email: qinyu100@outlook.com
}

\begin{abstract}
With the rapid development of urbanization, the problem of urban living environment is becoming more and more prominent, and the health of urban population is facing serious threat. Improving the environmental quality of urban settlements, changing the management model of settlements and guiding healthy lifestyles are important aspects towards human health. Based on the health perspective and goal, this paper analyzes the relationship between the residential environment and human health, as well as the common environmental health problems in the residential area, and studies and puts forward the design suggestions of the urban residential environment, which aims to make positive exploration for promoting the construction of healthy cities and achieving the goal of healthy living.
\end{abstract} Keywords: health, healthy living, urban settlements, environmental design

\section{INTRODUCTION}

Health is the most basic condition for human survival and reproduction. After entering the industrial revolution, the ecological environment is seriously damaged, the population is concentrated, the disease is frequent, and the human health problem is seriously threatened. In China, with the continuous acceleration of urbanization, the quality of urban living environment and the health status of residents caused by excessive population agglomeration are becoming more and more prominent, and the healthy life of urban people is facing great challenges. In recent years, not only all kinds of chronic diseases and psychological diseases are becoming more and more common, but also the widespread epidemic trend is occasionally erupting. For example, the SARS of 2003 once put the country in a panic. At the beginning of 2020, a terrible virus called COVID-19 began to spread in Wuhan, China. Subsequently, the United States, Italy, Spain and other countries have also erupted on a large scale. As of 3 April 2020, WHO released epidemic data showing more than 1 million confirmed cases and more than 50,000 deaths worldwide.[1] The rapid spread of the epidemic has pushed human health problems to the forefront again, and has put forward profound doubts and thoughts on the development of urban human settlements environment.

\section{ENVIRONMENTAL HEALTH IN URBAN SETTLEMENTS}

With the health problem being brought into the research category of human settlement environment construction, "healthy city" and "healthy community" have been put forward and paid attention to one after another.[2] As the goal and vision of urban development, the realization of healthy city needs to start from its basic unit -- Settlements. Therefore, the health of residential environment is most closely related to the health of urban habitat environment.

\subsection{Relationship Between The Habitat Environment And Human Health}

Urban residential area is an important space carrier of urban people's living life, and the main living place that people must face daily. The environmental quality of settlements has a direct impact on the physical and mental health of the population, mainly reflected in the following aspects:

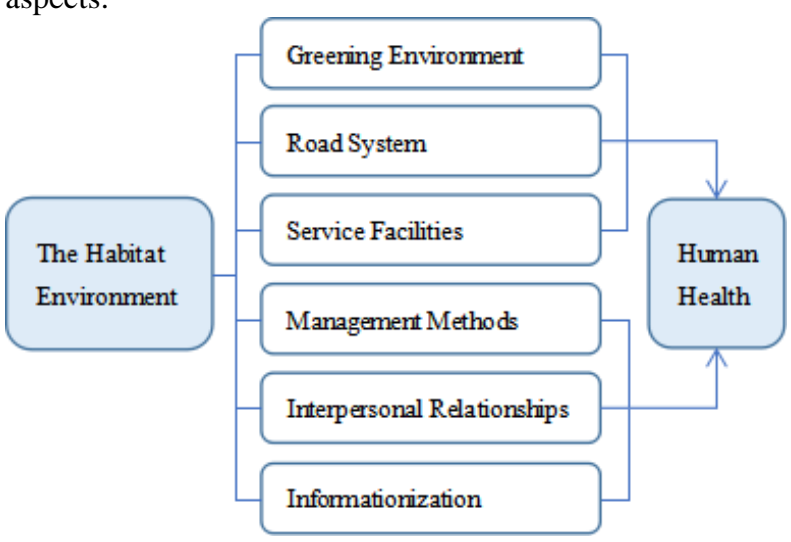

Figure 1 Relationship Analysis

First, the greening environment has an impact on health. The greening environment of residential area is usually manifested in green space rate, green plant variety, green 
landscape and so on. It can not only affect the small climate of residential areas, create a good ecological environment, but also improve stress and mental fatigue, increase outdoor activities and social will, reduce the probability of illness, and have a positive effect on health promotion in some studies. Second, the road system has an impact on health. The road traffic design of residential area is related to the safety, convenience and health of people's daily travel and outdoor activities, including whether the dynamic traffic is hierarchical, whether the static traffic is properly designed and distributed, and whether the various transportation facilities are perfect, and so on. Third, service facilities have an impact on health. The service facilities of the residential area include commercial department stores, logistics express delivery, health care, publicity and display, fitness and leisure, and others that related to daily life. The more perfect the matching, the more convenient life and the higher health index. Fourth, management methods have an impact on health. The daily management of open or closed way to carry on the daily management, mainly relates to the settlement security. we should not only consider the management effectiveness and convenience of daily life, but also consider the special needs of wartime state in design. Fifth, interpersonal relationships have an impact on health. The interpersonal relationship in the residential environment can have an important impact on mental health, mainly in the positive and friendly interpersonal relationship makes people feel comfortable. On the contrary, it is easy to produce depression, irritability and other negative emotions. Some studies have shown that most diseases such as cancer and depression are caused by a lack of normal social interaction.[3] Sixth, informationization has an impact on health. Informationization is an important product of contemporary scientific and technological progress, and the level of informationization of residential areas reflects the scientific and technological nature and advanced nature of residential management, which can promote the efficient and orderly development of daily work in residential areas and make the residential environment more intelligent.

\subsection{Common Problems Of The Residential Environment}

\subsubsection{Low Landscape Quality And Poor Sanitation}

The greening vegetation and landscape environment of residential areas are the most concerned by residents, and a good greening landscape environment can create a good ecological environment quality and benefit the health of the body. At the same time, it can also bring good mood and feeling, and guide more outdoor activities behavior. However, in the present situation, the landscape quality of some completed settlements is often poor, mainly manifested in less green area, single green plant variety, poor maintenance and management, poor sanitary condition, prominent problems of random stacking, and so on. The greening environment affects the ecological environment quality of the whole residential area, and also reduces people's psychological pleasure and enthusiasm for activities.

\subsubsection{Lack Of Service Facilities And Insufficient Venues}

The service facilities are the related supporting facilities which serve people's daily life and guarantee daily life. Such facilities, if not well equipped, can affect all aspects of life. The commercial and logistics service facilities in the residential area are not perfect, so it is difficult to meet the daily purchasing demand. Inadequate health care facilities and inability to provide consultation and guidance services. The lack of publicity and display facilities is easy to lead to poor communication due to lack of publicity, and ultimately the lack of humanistic atmosphere in residential areas, no cohesion. The lack of leisure fitness facilities has greatly reduced the possibility and enthusiasm of people's outdoor activities, and the long-term lack of exercise will lead to the emergence of chronic diseases such as obesity.

\subsubsection{Over-Open Design, Low Residential Security}

In recent years, many settlements have adopted a completely open design method, removing fences and setting up no gates, so that settlements can be fully integrated into urban space and integrated with urban streets and business circles. This so-called open settlement breaks the independence and privacy that the settlement should have, and the situation is frequent after it is built and occupied. Social personnel and vehicles enter and leave at will, the security of residential areas and even residents' privacy are seriously violated, burglary and robbery incidents continue to occur, residents complain. Especially now, at the time of the outbreak of a large-scale epidemic in the country, the control weakness of this type of residential area is more prominent, which brings great inconvenience to the prevention and control of the epidemic. 
avoid emotional depression, tension and anxiety caused by improper design.

\subsubsection{Less Humane Care, Inefficient Management}

In the construction management of urban settlements, in addition to the external living environment, its inner humanistic spirit is also very important. But most of the time the hardware part is fine, the software part is not enough. On the one hand, urban people work under great pressure, mental health problems are more and more, need timely attention and active guidance. On the other hand, in the face of the arrival of today's aging society, care for the elderly residential groups is relatively weak. In addition, the problem of backwardness and inefficiency is also common in the management of residential areas, the cost of labor input is more, the docking of demand and service is not correct, the communication of information is not smooth, and the statistics are insufficient, which needs to be improved.

\subsection{Health Requirements Of The Residential Environment}

By investigating and analyzing the common problems of the existing residential environment, the urban residential environment should have the following characteristics from the perspective of guiding healthy life:

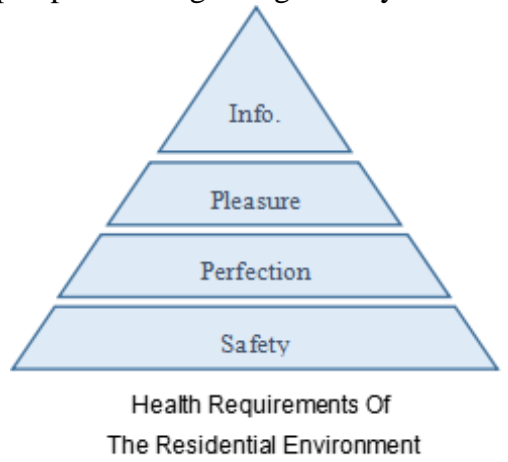

Figure 2 Health Environmental Characteristics

\subsubsection{Safety}

Safety is the most basic requirement based on the concept of health. A healthy residential environment should satisfy both physical and mental security, i.e. both physical and mental security. The safety of the material environment mainly depends on the relevant design specifications to check, the design is reasonable and the scale is suitable. The sense of security in the spiritual environment comes from the orderly and accessible design of the space environment, as well as the human and social environment of friendly and mutual assistance in residential areas, to

\subsubsection{Perfection}

The degree of improvement of residential service facilities reflects the living quality of residential areas and is an important guarantee for the convenience and well-being of life. The service facilities of the residential area mainly include commercial logistics, health care, fitness and leisure, publicity and display, etc. Each kind of facilities is closely related to people's daily life. The more complete the set, the more convenient of life, the more smooth the information exchange, the more selective outdoor activities, then, the health index of life is higher .

\subsubsection{Pleasure}

Pleasure is a requirement after basic life is guaranteed. Pleasure can come from many aspects, such as beautiful landscape, friendly interpersonal relationships, rich leisure activities and so on. It is not only the embodiment of residence satisfaction, but also an important measure of healthy life. Research shows that many diseases are caused by long-term psychological depression and depressed life. The city crowd life pressure is big, the work rhythm is fast, very easy to produce the psychological and the physiological disease, therefore maintains the inner health joyful is very important.

\subsubsection{Informatization}

With the rapid development of information technology, no individual or group can exist independently from the information network. In the face of the increasingly complex residential service requirements, the traditional community management model has become difficult to cope with. Therefore, the introduction of information technology into residential area management, the use of the Internet to build an intelligent residential area personnel management and information release service platform, will help to improve the level of residential management, improve service quality, and also help to realize the regular disease prevention and control of residential areas, and lay the foundation for the construction of intelligent cities and healthy cities.[4] 


\section{DESIGN PROPOSALS FOR OUTDOOR ENVIRONMENT IN URBAN SETTLEMENTS}

Residential outdoor environment usually consists of road traffic around residential buildings, planting greening, activity sites, service facilities, and management systems. Starting from the requirement of healthy living, the following aspects should be fully considered in the outdoor environment design of urban settlements:

\subsection{To Improve The Greening Environment}

The greening environment of residential area is the main aspect that affects the ecological environment quality of residential area, it is related to the ecological effect, beautification degree, people's way of life and psychological feeling of residential area. This is because the green space can not only purify the air, adjust the regional temperature and humidity, improve the microclimate; but also beautify the environment, enhance the mood, attract people to take a leisure walk, which is quite beneficial to physical and mental health. The improvement of greening environment depends on the green landscape design of residential areas. First of all, from the selection and planting of green plants, it needs to be considered from the regional, functional and diverse perspectives. Territoriality is reflected in the selection of plants suitable for climate characteristics, or the selection of some popular species with regional characteristics. The function is that the green plants can play a certain auxiliary role, such as broad-leaved plants have strong ornamental, evergreen four seasons, can shade the sun and avoid the sun, and photosynthesis is sufficient, which can help to improve air quality and regulate the climate. Diversity mainly refers to the appearance of landscaping effect can be appropriate rich and colorful. For example, planting different flowering plants and different types of fruit trees can produce beautiful and interesting greening effects in different seasons and time periods. Similarly, breaking through the traditional plane planting, through flower stands, pavilions, corridors, walls, balconies, roofs and other components can create three-dimensional green landscape, with rich levels to achieve a better landscape effect.

\subsection{To Make Clear The Road Traffic System}

The road traffic of residential area is an important link to the spatial elements of residential environment, which is related to people's daily travel and activities. Residential road traffic systems can be distinguished by dynamic and static traffic. All kinds of roads, passageways, corridors and so on, which meet the needs of people and vehicles, belong to dynamic traffic, and the places that meet the parking of vehicles and the rest of the crowd are static traffic. Healthy residential environment, need to build clear road traffic system. First, reasonable planning of passenger and vehicle routes, as far as possible to achieve passenger and vehicle branches, do not interfere with each other. Second, the appropriate division of road levels, according to the "residential ring road -- main road -landscape path" three levels of design. Third, promote the construction of residential health trails, provide residents with a morning run, stroll leisure fitness environment. Fourth, do a good job of static traffic design, including motor vehicles and non-motor vehicle temporary parking points, as well as residential rest areas and so on. Fifth, it is proposed to add accessibility facilities to meet the needs of the elderly, disabled wheelchairs and baby carts. Sixth, different road types can realize interface cues through different paving, which can not only increase aesthetic feeling, but also increase green space rate, but also realize ecological cycle. Seventh, appropriate supplement of street lights, ground lights, ring islands, signs and other transportation facilities to improve the living environment.[5]

\subsection{To Improve The Service Facilities}

The service facilities mainly provide services for residents' daily purchasing, medical treatment, leisure, entertainment and other activities, and whether the supporting facilities are perfect or not reflects the living convenience and living quality of the residential area. Commercial facilities, close to the daily life of residents, including supermarkets, restaurants, express delivery and so on. Medical facilities, such as health clinics, medical clinics, pharmacies and so on, should be allocated to each settlement of more than 10,000 people. Cultural facilities, such as activity rooms for the elderly, libraries, residential clubs and so on, provide people with space for cultural activities and learning to read. Sports facilities, such as indoor and outdoor stadiums, activity square, recreation and sports facilities, are the residential sports activities, reflect the spirit of the concentrated place. Leisure facilities, mainly some leisure service facilities in the outdoor space environment of residential areas, such as leisure seats, wind and rain promenades, exchange and so on, are important places for leisure and exchange, and can also become important landscape nodes in the residential environment. Publicity facilities, is an important window to promote public information and display residential culture, can be combined with the entrance space, leisure space, road square and other environments to set up.

\subsection{To Promote The Closed Settlements As Leading}

The safety of residential environment has always been the most important aspect of residential construction and management. Practice shows that many open residential 


\section{SUMMARY}

on the contrary, management contradictions are prominent, security risks are numerous. Complex entry and exit personnel, frequent adverse events, serious environmental damage... Should settlements choose open or closed design and management? After 2020 against the outbreak of new coronary pneumonia, more fully see the full open settlement of many drawbacks. Therefore, a healthy urban settlement environment should be a relatively closed, selfcontained and manageable living environment. It should have continuous and closed external enclosure components, easy to independently manage the entrance access, a fast and efficient closed management system. In the future, whether under the normal operation or in the emergency response, urban settlements advocate "closed design + closed management" as the leading, to ensure residential safety, improve management effectiveness.

\subsection{To Build an intelligent management system}

The construction and management of residential areas should be adapted to the development of the times, social progress the desire of demand. Under the background of the rapid development of the Internet, the management of residential areas can not be separated from the support of Internet technology, and should be integrated into the large network of information technology. The traditional residential management mostly adopts the manual mode, the manpower demand is big, the management efficiency is low, the means way is backward. With the continuous advancement of the national and even global grid information technology, the settlement management has the foundation of intelligent development. The intelligent management system insists on people-oriented and service-oriented, relies on the grid construction of residential management, uses cloud computing technology to detect and manage the population, health, facilities, environment, behavior and other information data of residential areas, carries out daily service, propaganda, emergency and other work, and can realize intelligent health, intelligent old-age care, intelligent housekeeping and other fine services.[6] Intelligent management not only reduces the input of manpower and material resources, improves the efficiency of regular management, but also can effectively deal with the safety monitoring, information statistics and psychological intervention in special periods, do a good job of disaster prevention to the maximum extent, reduce all kinds of effects, and make residential areas become a part of urban safety and health, easy to prevent and control.
Healthy living is the way of life that every citizen yearn for. And settlements are the main places to carry and embody this way of life. Therefore the health of the residential environment is crucial. Starting with the common maladies of the residential environment and the basic characteristics of the healthy residential area, this paper puts forward some suggestions for the environmental design of urban settlements, which is based on the analysis and thinking of outdoor environmental planning. However, building a healthy settlement requires the participation of all parties, and so, this paper just hopes to arouse more attention to the environmental health of urban settlements and build a better urban living environment.

\section{REFERENCES}

[1] http://news.cri.cn/20200404/f5438a2f-e2a4-a3d22d2b-4b77b1c18f2f.html

[2] Wang Yi, Healthy City Oriented Community Planning, Planners. 31(10) (2015) 101-105.

[3] Guo T H, Study on Social-Ecological Moderators Differing the Relation between Urban Green Space and Human Health[J], Journal of Human Settlements in West China. 34(3) (2019) 35-41. DOI: https://doi.org/10.13791/j.cnki.hsfwest.20190305

[4] Ma Lei, Intelligent City Community Information Solution-Intelligent Community Planning Scheme, Telecom Power Technology. 36(01) (2019) 240-241. DOI://doi.org/10.19399/j.cnki.tpt. 2019.01.096

[5] Li Chunju, Jiang Guaini, Liu Xiaoqian, Study on the Construction of Residential Walking System Oriented Low-Carbon Transportation, Modern Urban Research. 06(2017) 121-127. DOI:

https://doi.org/10.3969/j.issn.1009-6000.2017.06.017

[6] Zhang Congcong, Wang Juan, Xu Xiaolin, Liu Xu, Study of Community Informatization Governance From Digital Community to Smart Community, Journal of Modern Information. 39(5) (2019) 143-155. DOI: https://doi.org/10.3969/j.issn.1008-0821.2019.05.019 